Article

\title{
Study of $n$-Butyl Acrylate Self-Initiation Reaction Experimentally and via Macroscopic Mechanistic Modeling
}

\author{
Ahmad Arabi Shamsabadi ${ }^{1}$, Nazanin Moghadam ${ }^{1}$, Sriraj Srinivasan ${ }^{2}$, Patrick Corcoran ${ }^{1}$, \\ Michael C. Grady ${ }^{3}$, Andrew M. Rappe ${ }^{4}$ and Masoud Soroush 1,* \\ 1 Department of Chemical and Biological Engineering, Drexel University, Philadelphia, PA 19104, USA; \\ ahmad.arabishamsabadi@drexel.edu (A.A.S.); nznnmoghadam@gmail.com (N.M.); phc28@drexel.edu (P.C.) \\ 2 Arkema Inc., 900 1st Avenue, King of Prussia, PA 19406, USA; sriraj.s@gmail.com \\ 3 DuPont Experimental Station, Wilmington, DE 19803, USA; michael.c.grady-1@dupont.com \\ 4 The Makineni Theoretical Laboratories, Department of Chemistry, University of Pennsylvania, Philadelphia, \\ PA 19104-6323, USA; rappe@sas.upenn.edu \\ * Correspondence: ms1@drexel.edu; Tel.: +1-215-895-1710
}

Academic Editor: Michael Henson

Received: 14 February 2016; Accepted: 15 April 2016; Published: 23 April 2016

\begin{abstract}
This paper presents an experimental study of the self-initiation reaction of $n$-butyl acrylate ( $n$-BA) in free-radical polymerization. For the first time, the frequency factor and activation energy of the monomer self-initiation reaction are estimated from measurements of $n$-BA conversion in free-radical homo-polymerization initiated only by the monomer. The estimation was carried out using a macroscopic mechanistic mathematical model of the reactor. In addition to already-known reactions that contribute to the polymerization, the model considers a $n$-BA self-initiation reaction mechanism that is based on our previous electronic-level first-principles theoretical study of the self-initiation reaction. Reaction rate equations are derived using the method of moments. The reaction-rate parameter estimates obtained from conversion measurements agree well with estimates obtained via our purely-theoretical quantum chemical calculations.
\end{abstract}

Keywords: free-radical polymerization; spontaneous thermal polymerization; monomer self-initiation; method of moments; $n$-butyl acrylate

\section{Introduction}

Acrylic polymers are used widely in coatings, as adhesives and functional additives. Increasingly tight limits on volatile organic contents of paints and coatings [1,2] have required the paints and coatings industries to decrease the level of solvents in their products. To ensure adequate brushability and sprayability of the low (20-40 $\mathrm{wt} \%)$ solvent-content paint and coatings, polymers with low average molecular weights $\left(\bar{M}_{w}<10,000\right)$ have been produced via high-temperature $\left(120-190^{\circ} \mathrm{C}\right)$ polymerization processes [3-5]. At these high temperatures, secondary reactions such as monomer self-initiation, $\beta$-scission, inter/intra-molecular chain transfer and backbiting reactions are influential and thus require study [6].

Thermal polymerization of alkyl acrylates in the absence of external initiators has been reported [7]. The occurrence of monomer self-initiation reaction allows one to use less thermal initiators, typically organic peroxides or azonitriles, which are relatively expensive and as residues can cause defects in the final product, especially on weathering [8]. Studies using electron spray ionization-Fourier transform mass spectrometry (ESI-FTMS), nuclear magnetic resonance (NMR) spectroscopy, and macroscopic mechanistic modeling did not identify the initiating species or the mechanism of initiation in the spontaneous thermal polymerization [7,9]. However, quantum chemical calculations [10-13] together 
with matrix-assisted laser desorption ionization (MALDI) [14] showed that monomer self-initiation is one of the likely mechanisms of initiation in spontaneous thermal polymerization of alkyl acrylates.

Polymer characterization studies using spectroscopic methods have been carried out to explore the dominant polymerization reactions [7,9]. Pulsed-laser polymerization (PLP) and size exclusion chromatography have been used to study intra-molecular chain transfer to polymer (CTP) reactions in polymerization of alkyl acrylates $[15,16]$. The rate coefficients of the propagation reactions of styrene [17], and methyl methacrylate (MMA) [18], and chain transfer reactions of butyl methacrylate (BMA) [19] at temperatures above $30^{\circ} \mathrm{C}$ have been estimated using PLP. Although the propagation rate coefficient of $n$-butyl acrylate ( $n$-BA) at $70^{\circ} \mathrm{C}$ has been calculated using PLP at $500 \mathrm{~Hz}$ [20], the presence of backbiting and $\beta$-scission reactions has hindered the prediction of alkyl acrylates' propagation rate coefficient at elevated temperatures [21-23]. At temperatures above $30{ }^{\circ} \mathrm{C}$, intra- and inter-molecular CTP reactions in free-radical polymerization of $n$-BA $[24,25]$ and intra-molecular CTP reactions in 2-ethylhexyl acrylate polymerization [26] have also been studied using NMR spectroscopy. Although these analytical techniques have been very useful in characterizing acrylate polymers, they alone cannot conclusively determine reaction mechanisms or estimate kinetic parameters of reactions. Macroscopic mechanistic modeling combined with adequate polymer sample measurements has proven to be a powerful tool to estimate the rate coefficients of individual reactions. Macroscopic mechanistic models have also been used extensively to estimate the rate coefficients of initiation by conventional thermal initiators, propagation, chain transfer and termination reactions in free-radical polymerization of acrylates [9,16,27-32]. Kinetic parameters of several reactions in spontaneous thermal polymerization of $n$-BA under seemingly oxygen-free conditions (solvent was bubbled with nitrogen but not $n$-BA, and a nitrogen blanket was used inside the reactor) were estimated through detailed macroscopic mechanistic modeling, and the entire initiation was attributed to monomer self-initiation, leading to an unrealistically-large self-initiation rate coefficient [9]. Styrene and MMA self-initiation apparent rate coefficients estimated through macroscopic mechanistic modeling have been reported [27,28]. A macroscopic mechanistic model of $n$-BA spontaneous polymerization, which accounted for initiation only by the monomer, was used to estimate the $n$-BA self-initiation rate coefficient from measurements of conversion under seemingly oxygen-free conditions [9], again leading to a very large reaction rate coefficient for monomer self-initiation, because the entire monomer conversion was attributed to initiation only by the monomer [29].

Macroscopic mechanistic polymerization models are more useful than semi-empirical models. The accuracy of mechanistic polymerization models strongly depends on our quantitative understanding of individual reactions occurring during the course of polymerization. These models have been used to study low and high-temperature polymerization reactions of $n$-BA $[33,34]$. The method of moments [35-37] or the "tendency modeling" approach [38-41] can be used to derive rate equationsneeded in macroscopic mechanistic models. Models obtained using the tendency-modeling rate equations do not account for the number of monomer units in polymer chains, and therefore they are less complex than models that are based on the method-of-moments rate equations. Models that are based on the method of moments can be used to estimate kinetic rate coefficients more accurately. Applications of both types of models can be found in the literature [42-46].

In our previous work, we studied self-initiation of alkyl acrylates such as methyl, ethyl and n-butyl acrylate as well as methyl methacrylate theoretically using density functional theory [10-13]. We found that self-initiation of alkyl acrylates has three elementary reaction steps in series:

(i) Two monomers react and form a singlet diradical

$$
M+M \quad \rightarrow \quad * M M_{S}^{*}
$$

(ii) The singlet diradical then undergoes intersystem crossing to form a triplet diradical:

$$
{ }^{*} M M_{s}^{*} \quad \rightarrow \quad * M M_{t}^{*}
$$


(iii) The triplet diradical finally reacts with a third monomer, leading to the formation of two mono-radicals:

$$
{ }^{*} M M_{t}^{*}+M \quad \rightarrow \quad M M^{*}+M^{*}
$$

We also calculated the kinetic parameters of the three preceding reactions [10-12]. The first reaction is the fastest reaction, whereas the second reaction is the slowest (rate limiting) reaction. Therefore, the overall (apparent) self-initiation reaction:

$$
3 M \quad \stackrel{k_{i}}{\rightarrow} M M^{*}+M^{*}
$$

is second order.

In this paper, we experimentally estimate the kinetic parameters (activation energy and frequency factor) of the overall (apparent) $n$-BA self-initiation reaction in Equation (4) from monomer conversion measurements using a macroscopic mechanistic polymerization reactor model guided by our first-principles investigations of the mechanism. These estimates are compared with our existing estimates of the same parameters obtained via quantum chemical calculations.

The organization of the rest of this paper is as follows. Section 2 presents the mathematical model. Section 3 discusses the experimental and analytical procedures. Section 4 describes the parameter estimation study. Finally, concluding remarks are given in Section 5.

\section{Mathematical Modeling}

\subsection{Reaction Mechanisms}

The most likely polymerization reactions occurring in spontaneous thermal solution polymerization of $n$-BA in the absence of oxygen are given in Table 1 . The reactions include monomer self-initiation [10-12], secondary and tertiary chain propagation, intra-molecular chain transfer to polymer (backbiting), inter-molecular chain transfer to polymer, $\beta$-scission, chain transfer to monomer [47], chain transfer to solvent, termination by combination, and termination by disproportionation reactions [48,49]. While not all of these reactions strongly affect monomer conversion, the list of the reactions is given here for completeness. For example, no solvent has been used in the study presented herein. Here, $M$ and $S$ denote the monomer and solvent, respectively. $U_{n}$ represents a dead polymer chain with $n$ monomer units and a terminal double bond. $D_{n}$ is a dead polymer chain with $n$ monomer units but without a terminal double bond. $R_{n}{ }^{*}$ represents a secondary radical with $n$ monomer units. $R_{n}{ }^{* *}$ is a tertiary radical with $n$ monomer units generated through intermolecular CTP reactions. $R_{n}{ }^{* * *}$ denotes a tertiary radical with $n$ monomer units formed by backbiting reactions. SCB and LCB represent a short and a long chain branching point, respectively.

Table 1. Polymerization reactions [34].

a. Apparent monomer self-initiation reaction

$$
3 M \stackrel{k_{i}}{\rightarrow} R_{1}^{*}+R_{2}^{*}
$$

b. Propagation reactions

$$
\begin{gathered}
R_{n}^{*}+M \stackrel{k_{p}}{\rightarrow} R_{n+1}^{*} \\
R_{n}^{* *}+M \stackrel{k_{p}^{t}}{\rightarrow} R_{n+1}^{*}(+\mathrm{LCB}) \\
R_{n}^{* * *}+M \stackrel{k_{p}^{t}}{\rightarrow} R_{n+1}^{*}(+\mathrm{SCB}) \\
R_{n}^{*}+U_{m} \stackrel{k_{m a c}}{\rightarrow} R_{n+m}^{* *}
\end{gathered}
$$

c. Backbiting reactions $(n>2)$

$$
R_{n}^{*} \stackrel{k_{b b}}{\longrightarrow} R_{n}^{* * *}
$$


Table 1. Cont.

d. $\beta$-scission reactions $(n>3)$

$$
\begin{aligned}
& R_{n}^{* * *} \stackrel{\stackrel{k_{\beta}}{\rightarrow}}{\rightarrow} U_{3}+R_{n-3}^{*} \\
& R_{n}^{* * *} \stackrel{k_{\beta}}{\rightarrow} R_{n-3}^{*}+U_{3} \\
& R_{n}^{* * *} \stackrel{k_{\beta}}{\rightarrow} U_{n-2}+R_{2}^{*} \\
& R_{n}^{* * *} \stackrel{k_{\beta}}{\rightarrow} R_{2}^{*}+U_{n-2} \\
& R_{n}^{* *} \stackrel{k_{\beta}}{\rightarrow} U_{n-m}+R_{m}^{*} \\
& R_{n}^{* *} \stackrel{k_{\beta}}{\rightarrow} R_{m}^{*}+U_{n-m}
\end{aligned}
$$

e. Intermolecular chain transfer to polymer reactions

$$
\begin{array}{ll}
R_{n}^{*}+D_{m} \stackrel{m k_{t r} P}{\longrightarrow} & D_{n}+R_{m}^{* *} \\
R_{n}^{*}+U_{m} \stackrel{m k_{t r P}}{\longrightarrow} & D_{n}+R_{m}^{* *}
\end{array}
$$

f. Chain transfer to monomer reactions

$$
\begin{gathered}
R_{n}^{*}+M \underset{n}{\stackrel{k_{t r M} M}{\rightarrow}} D_{n}+R_{1}^{*} \\
R_{n}^{* *}+M \underset{t r m}{\stackrel{k_{t r M}^{t}}{\rightarrow}} D_{n}+R_{1}^{*} \\
R_{n}^{* * *}+M \stackrel{k_{t r M}^{t}}{\rightarrow} D_{n}+R_{1}^{*}
\end{gathered}
$$

g. Chain transfer to solvent reactions

$$
\begin{array}{cc}
R_{n}^{*}+S \underset{t r s}{\stackrel{k_{t r S}}{\rightarrow}} D_{n}+R_{0}^{*} \\
R_{n}^{* *}+S \underset{t r S}{\stackrel{k_{t r}}{\rightarrow}} D_{n}+R_{0}^{*} \\
R_{n}^{* * *}+S \stackrel{k_{t r s}^{t}}{\rightarrow} D_{n}+R_{0}^{*}
\end{array}
$$

h. Termination by coupling reactions

$$
\begin{aligned}
& R_{n}^{*}+R_{m}^{*} \stackrel{k_{t c}}{\rightarrow} D_{n+m} \\
& R_{n}^{*}+R_{m}^{* *} \stackrel{2 k_{c}^{t}}{\rightarrow} D_{n+m} \\
& R_{n}^{*}+R_{m}^{* * *} \stackrel{2 k_{t c}^{t}}{\rightarrow} D_{n+m} \\
& R_{n}^{* *}+R_{m}^{* *} \stackrel{k_{t \rightarrow}^{H t}}{\stackrel{H}{t}} D_{n+m} \\
& R_{n}^{* *}+R_{m}^{* * *} \stackrel{2 k_{t}^{H t}}{\rightarrow} D_{n+m} \\
& R_{n}^{* * *}+R_{m}^{* * *} \stackrel{k_{t t}^{t t}}{\rightarrow} D_{n+m}
\end{aligned}
$$

i. Termination by disproportionation reactions

$$
\begin{aligned}
& R_{n}^{*}+R_{m}^{*} \stackrel{k_{t d}}{\longrightarrow} D_{n}+U_{m} \\
& R_{n}^{*}+R_{m}^{* *} \stackrel{k_{t d}^{t}}{\rightarrow} D_{n}+U_{m} \\
& R_{n}^{*}+R_{m}^{* *} \stackrel{k_{t d}^{t}}{\longrightarrow} D_{m}+U_{n} \\
& R_{n}^{*}+R_{m}^{* * *} \stackrel{k_{t d}^{t}}{\longrightarrow} D_{n}+U_{m} \\
& R_{n}^{*}+R_{m}^{* * *} \stackrel{k_{t d}^{t}}{\rightarrow} D_{m}+U_{n} \\
& R_{n}^{* *}+R_{m}^{* *} \stackrel{k_{t d}^{t t}}{\rightarrow} D_{n}+U_{m} \\
& R_{n}^{* *}+R_{m}^{* * *} \stackrel{k_{t d}^{t t}}{\rightarrow} D_{n}+U_{m} \\
& R_{n}^{* *}+R_{m}^{* * *} \stackrel{k_{t d}^{H t}}{\longrightarrow} D_{m}+U_{n} \\
& R_{n}^{* * *}+R_{m}^{* * *} \stackrel{k_{t d}^{t t}}{\rightarrow} D_{n}+U_{m}
\end{aligned}
$$

Inter- and intra-molecular CTP reactions lead to the formation of tertiary radicals, which are capable of undergoing propagation [50] and $\beta$-scission reactions. The $\beta$-scission reactions produce secondary radicals and dead polymer chains with a terminal double bond. This led to the generation of shorter dead polymer chains, thus lowering the average molecular weight of the polymer product. 


\subsection{Rate Equations}

Reaction rate equations are derived using the method of moments. We assume that all reactions given in Table 1 except for the self-initiation reaction are elementary. As expected, accounting for $\beta$-scission and inter-molecular CTP reactions leads to closure problems; that is, a moment of a chain length distribution depends on a higher moment of the same or different distributions [36]. For example, as the inter-molecular CTP reaction rate coefficient depends on the number of polymerized monomer units in the dead polymer chains, the zeroth moments of the chain length distributions of the dead polymer chains depend on their first moments. To address this problem, for each chain length distribution, a specific distribution model is assumed to derive an approximation that relates the third moment of the distribution to lower moments of the same distribution. In particular, chain length distributions of the dead polymer chains with or without a terminal double bond are assumed to be re-scaled Gamma distributions [51], and the chain length distribution of the tertiary radicals $R_{n}^{* *}$ is assumed to have a normal distribution.

The resulting rate equations; that is, the production rate equations for $M, S, R_{0}{ }^{*}, R_{1}{ }^{*}, R_{2}{ }^{*}, R_{3}{ }^{*}$, and the zeroth, first, and second moments of dead polymer, secondary radical, and tertiary radical chain length distributions, are given in the Appendix. $[X]$ represents the molar concentration of species $X . \delta_{0}{ }^{*}, \delta_{1}{ }^{*}$, and $\delta_{2}{ }^{*}$ are the zeroth, first, and second moments of the secondary radical chain length distributions. $\delta_{0}^{* *}, \delta_{1}^{* *}, \delta_{2}^{* *}$, and $\delta_{3}^{* *}$ are the zeroth, first, second, and third moments of the chain length distribution of the tertiary radicals generated by the intermolecular CTP reactions. $\delta_{0}^{* * *}, \delta_{1}^{* * *}$, and $\delta_{2}{ }^{* * *}$ are the zeroth, first, and second moments of the chain length distribution of the tertiary radicals formed by the backbiting reactions. The $j$ th moments of the chain length distributions of the live and dead polymer chains are:

$$
\begin{gathered}
\delta_{j}^{*}=\sum_{n=0}^{\infty} n^{j}\left[R_{n}^{*}\right], \quad \delta_{j}^{* *}=\sum_{n=1}^{\infty} n^{j}\left[R_{n}^{* *}\right], \quad \delta_{j}^{* * *}=\sum_{n=1}^{\infty} n^{j}\left[R_{n}^{* * *}\right] \\
\lambda_{j}=\sum_{n=1}^{\infty} n^{j}\left[D_{n}\right], \quad \Gamma_{j}=\sum_{n=1}^{\infty} n^{j}\left[U_{n}\right]
\end{gathered}
$$

and $\delta_{0}=\delta_{0}^{*}+\delta_{0}^{* *}+\delta_{0}^{* * *}$.

\subsection{Batch Reactor Model}

Mole balances on all species and balances on the moments lead to a batch reactor model that consists of 21 first-order ordinary differential equations:

$$
\frac{d[J]}{d t}=r_{J},[J](0)=[J]_{0}
$$

where $J=M, S, R_{0}^{*}, R_{1}^{*}, R_{2}^{*}, R_{3}^{*}, \delta_{0}^{*}, \delta_{1}^{*}, \delta_{2}^{*}, \delta_{0}^{* *}, \delta_{1}^{* *}, \delta_{2}^{* *}, \delta_{0}^{* *}, \delta_{1}^{* * *}, \delta_{2}^{* * *}, \lambda_{0}, \lambda_{1}, \lambda_{2}, \Gamma_{0}, \Gamma_{1}, \Gamma_{2}$. All initial concentrations are assigned to be zero except for that of monomer, which is nonzero and is denoted by $[\mathrm{M}]_{0}$. The monomer conversion is calculated using:

$$
X=\frac{[M]_{0}-[M]}{[M]_{0}}
$$

In this model, volume effects and diffusional limitations are ignored as most of conversion measurements reported herein are below 50\%. Also, depropagation is not considered, as it is insignificant for alkyl acrylate monomers. However, it is significant for methacrylate monomers [5].

\section{Experimental and Analytical Procedures}

The monomer, $98 \%$-butyl acrylate stabilized with $50 \mathrm{ppm}$ of 4-methoxyphenol as inhibitor, is from Alfa Aesar. Batch reactors are 4-inch stainless steel Swagelok tubes (Swagelok Inc., Huntingdon 
Valley, PA, USA), capped at both ends with Swagelok stainless steel caps. The 4-inch length gives a reaction volume of $4.8 \mathrm{~mL}$. These tubes can withstand pressures up to $3300 \mathrm{psig}$.

For each set of batch experiments, $30-50 \mathrm{~mL}$ of $n$-BA is dripped through an inhibitor removal column DHR-4, from Scientific Polymer Products of Ontario, New York, in order to remove the inhibitor. The inhibitor-free monomer is collected in a 50-mL round-bottom flask equipped with a standard taper 24/40 ground glass joint. After one hour of UHP nitrogen bubbling, we remove the needles and wrap the rubber septum tightly with aluminum foil secured with tight rubber bands. The round-bottom flask with the inhibitor-free, nitrogen-bubbled $n$-BA, the open reaction tubes, and the tube caps are then moved to the vacuum-nitrogen-purge chamber of a nitrogen-atmosphere glove box (LC Technology Solutions, Salisbury, USA). After several vacuum-nitrogen purge cycles, the flask, tubes and caps are then moved to the main chamber of the glove box, in which oxygen is removed reactively and water physically from the nitrogen gas inside. The oxygen concentration in the glove box is kept below $0.1 \mathrm{ppm}$. Inside the glove box, the sealed flask is then opened and $2.5 \mathrm{~mL}$ of monomer are pipetted into each reaction tube, after which the other end cap is attached and tightened. Upon removal from the glove box, each reaction tube is weighed, and the weight is recorded. The fluidized sand bath is then heated to a desired constant reaction temperature. After maintaining the sand bath at the desired temperature for several hours, two reactor tubes at a time are placed in the sand bath and are then pulled out of the fluidized sand bath after a specific period of time. The tubes are then cooled quickly in a cold water bath to stop further polymerization. After drying each tube, the reaction tube is weighed, and the weight is recorded. If any tube shows a weight loss, the tube is discarded from the experiment. The content of each tube is then emptied into vials. The time that a reactor tube spends in the sand bath minus one minute is considered as the reaction time of the reactor tube. Our previous studies had shown that it takes approximately one minute for the monomer inside a reactor tube to reach the sand bath temperature.

The conversion in each reaction tube is measured with a gravimetric method. A $57 \mathrm{~mm}$ aluminum dish is weighted (wgt1). Then, $1.5 \mathrm{~mL}$ of the reaction mass is pipetted from each vial into the aluminum dish, and the dish is then weighed (wgt2). Three milliliters of toluene is then added to the reaction mass, which completely dissolves in the added toluene. Next, the dish is placed in a vacuum oven overnight at $50{ }^{\circ} \mathrm{C}$ to allow the solvent and the unreacted monomer to evaporate. The dish is then weighed a third time (wgt3). The \% conversion is calculated using the equation $(($ wgt1 $-w g t 3) \times 100) /(w g t 1-w g t 2)$.

\section{Results and Discussion}

\section{Parameter Estimation}

Rate coefficients of all reactions except for the monomer self-initiation reaction are given in Table 2.

Table 2. Reaction rate coefficient values.

\begin{tabular}{ccccc}
\hline Parameter & \multicolumn{2}{c}{ Frequency Factor } & $\begin{array}{c}\text { Activation Energy } \\
\left(\mathbf{k J \cdot m o l} \mathbf{- 1}^{-\mathbf{1}}\right.\end{array}$ & Ref. \\
\hline$k_{p}$ & $2.21 \times 10^{7}$ & $\mathrm{~L} \cdot \mathrm{mol}^{-1} \cdot \mathrm{s}^{-1}$ & 17.9 & {$[30]$} \\
$k_{p}^{t}$ & $1.20 \times 10^{6}$ & $\mathrm{~L} \cdot \mathrm{mol}^{-1} \cdot \mathrm{s}^{-1}$ & 28.6 & {$[49]$} \\
$k_{b b}$ & $7.41 \times 10^{7}$ & $\mathrm{~s}^{-1}$ & 32.7 & {$[33]$} \\
$k_{t r M}$ & $2.90 \times 10^{5}$ & $\mathrm{~L} \cdot \mathrm{mol}^{-1} \cdot \mathrm{s}^{-1}$ & 32.6 & {$[47]$} \\
$k_{t}$ & $3.89 \times 10^{9}$ & $\mathrm{~L} \cdot \mathrm{mol}^{-1} \cdot \mathrm{s}^{-1}$ & 8.4 & {$[31]$} \\
$k_{t}^{t t}$ & $5.30 \times 10^{9}$ & $\mathrm{~L} \cdot \mathrm{mol}^{-1} \cdot \mathrm{s}^{-1}$ & 19.6 & {$[34]$} \\
$k_{\beta}$ & $1.49 \times 10^{9}$ & $\mathrm{~s}^{-1}$ & 63.9 & {$[34]$} \\
$k_{t r P}$ & $4.01 \times 10^{3}$ & $\mathrm{~L} \cdot \mathrm{mol}^{-1} \cdot \mathrm{s}^{-1}$ & 29.0 & {$[15]$} \\
$C_{t r S}$ & $1.07 \times 10^{2}$ & & 35.4 & {$[34]$} \\
\hline
\end{tabular}


Table 3. Reaction rate coefficient definitions and correlations [34,48].

$$
\begin{gathered}
k_{t}=k_{t c}+k_{t d} \\
k_{t}^{t}=k_{t c}^{t}+k_{t d}^{t} \\
k_{t}^{t t}=k_{t c}^{t t}+k_{t d}^{t t} \\
k_{t d}=\delta_{s} k_{t} \\
k_{t d}^{t t}=\delta_{t} k_{t}^{t t} \\
k_{t d}^{t}=\delta_{s t} \sqrt{k_{t} k_{t}^{t t}} \\
k_{t c}=\left(1-\delta_{s}\right) k_{t} \\
k_{t c}^{t t}=\left(1-\delta_{t}\right) k_{t}^{t t} \\
k_{t c}^{t}=\left(1-\delta_{s t}\right) \sqrt{k_{t} k_{t}^{t t}} \\
k_{t r S}=C_{t r s} k_{p} \\
k_{t r M}^{t}=\frac{k_{p}^{t}}{k_{p}} k_{t r M} \\
k_{\text {mac }}=\gamma k_{p}
\end{gathered}
$$

The unknown rate coefficient, $k_{\mathrm{i}}$, is estimated from monomer-conversion measurements. Reaction rate coefficient definitions, correlations and dimensionless kinetic parameter values are provided in Tables 3 and 4.

Table 4. Dimensionless kinetic parameter values [34,48].

\begin{tabular}{cc}
\hline Parameter & Dimensionless Value \\
\hline$\delta_{s}$ & 0.1 \\
$\delta_{s t}$ & 0.7 \\
$\delta_{t}$ & 0.9 \\
$\gamma$ & 0.5 \\
\hline
\end{tabular}

The system of ordinary differential equations (ODEs) is integrated numerically using the MATLAB routine bvp5c. For parameter estimation, the MATLAB function fminsearch, which is based on the Nelder-Mead simplex algorithm, is used to find the value of $k_{\mathrm{i}}$ that minimizes the sum of the squared errors between measurements and model-predicted values of conversion.

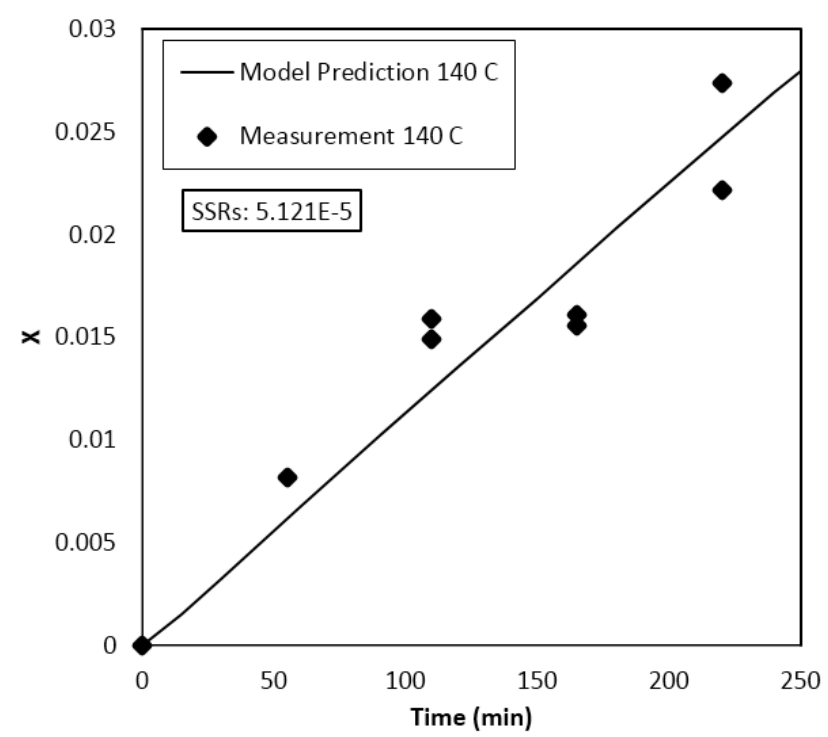

Figure 1. Measurements and model prediction of monomer conversion at $140{ }^{\circ} \mathrm{C}$. SSRs $=$ sum of squared residuals. 


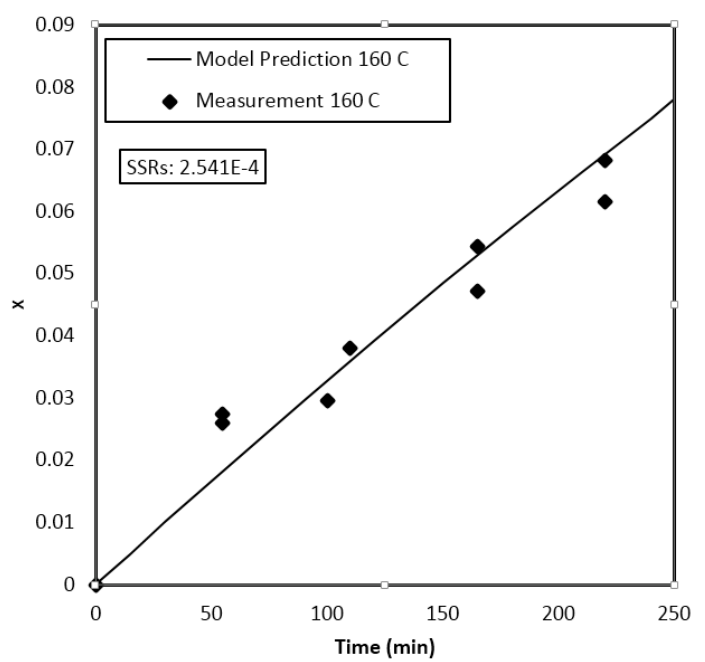

Figure 2. Measurements and model prediction of monomer conversion at $160^{\circ} \mathrm{C}$.

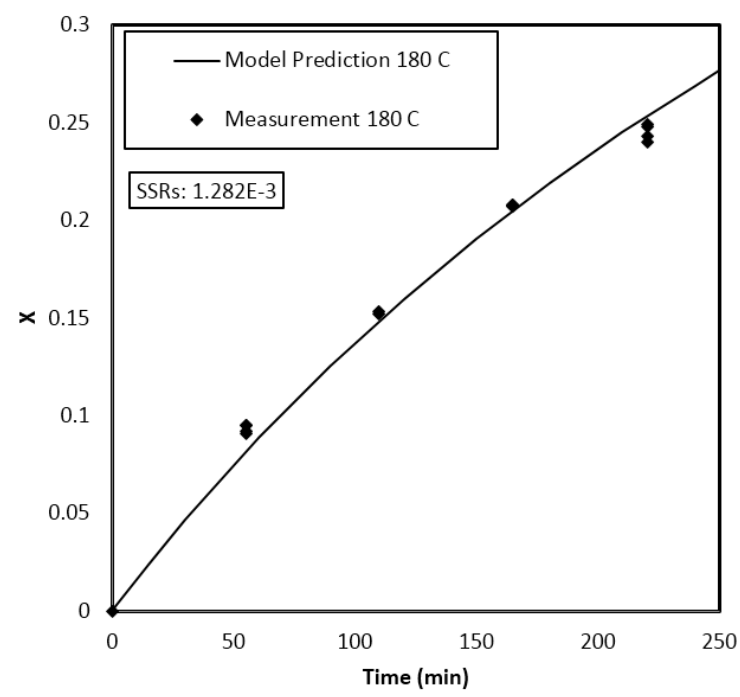

Figure 3. Measurements and model prediction of monomer conversion at $180{ }^{\circ} \mathrm{C}$.

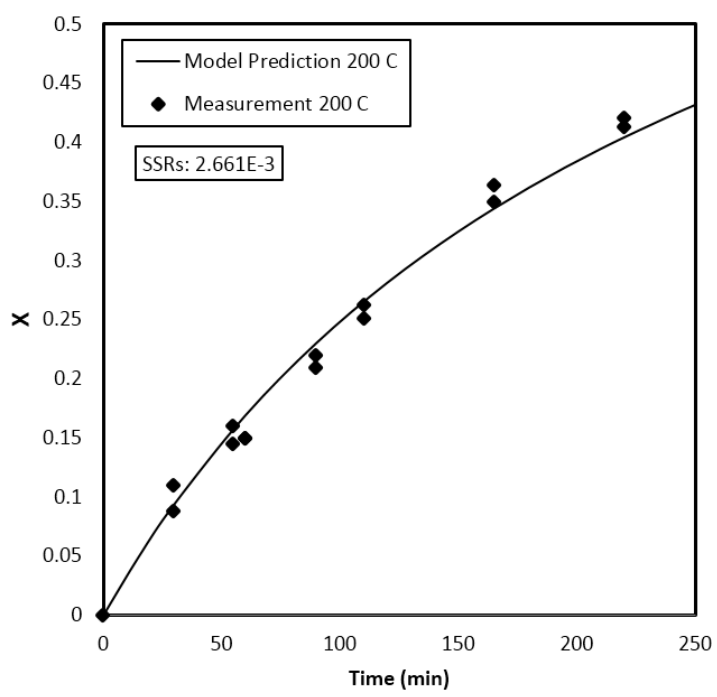

Figure 4. Measurements and model prediction of monomer conversion at $200{ }^{\circ} \mathrm{C}$. 
Figures 1-5 show measurements and model predictions of $n$-BA conversion at different constant reactor temperatures $\left(140,160,180,200\right.$ and $\left.220^{\circ} \mathrm{C}\right)$. At each temperature, $k_{\mathrm{i}}$, is estimated by fitting the model predictions to the measurements. As can be seen, the model fits the measurements very well at all four temperatures.

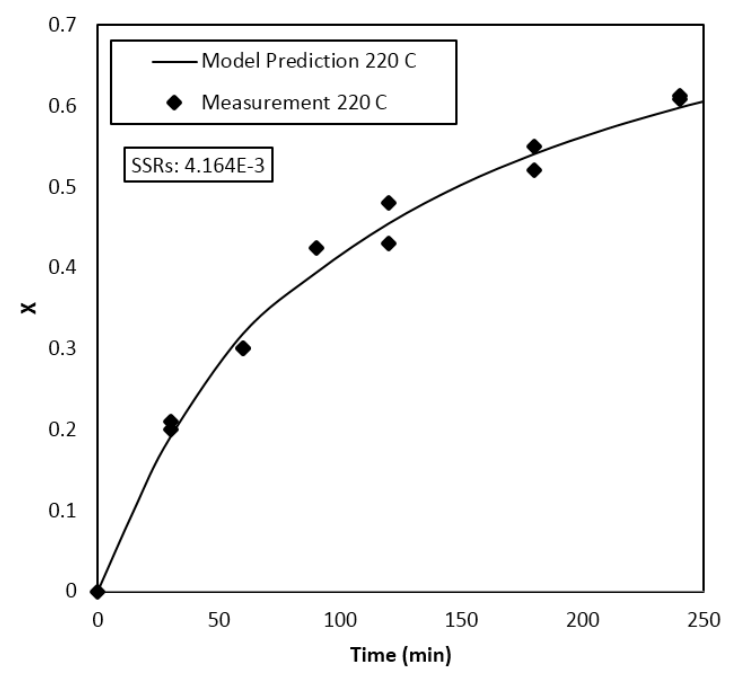

Figure 5. Measurements and model prediction of monomer conversion at $220^{\circ} \mathrm{C}$.

Once the reaction rate coefficient is estimated at $140,160,180,200$ and $220^{\circ} \mathrm{C}$, the reaction frequency factor and activation energy are estimated using the Arrhenius plot (see Figure 6).

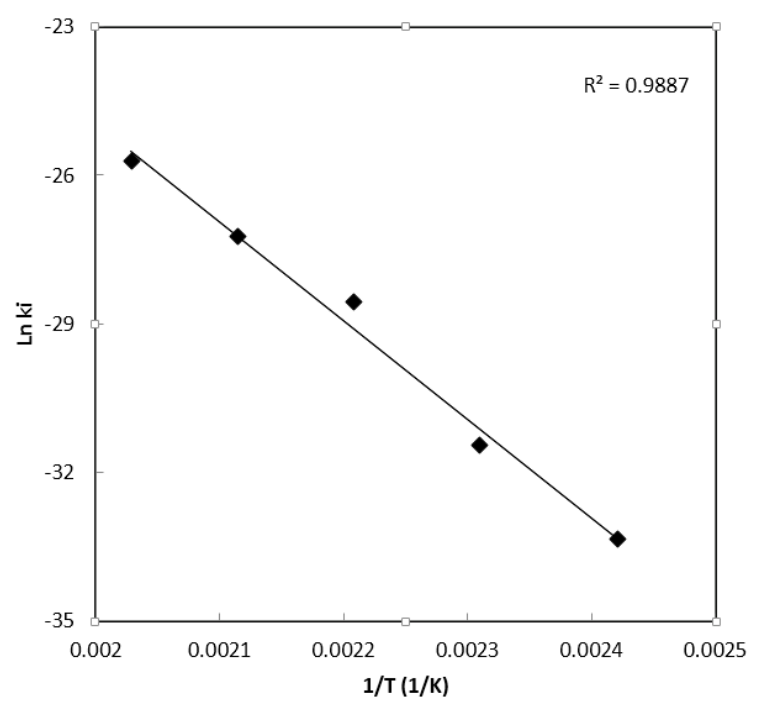

Figure 6. Arrhenius plot of $k_{i}$ to estimate $E_{i}$ and $A_{i}$.

The estimated frequency factor and activation energy as well as their $95 \%$ confidence intervals are given in Table 5. As can be seen in this table, the experimentally estimated self-initiation rate coefficients are in excellent agreement with those calculated using quantum chemical calculations (within a factor of 2-3 of those reported in [12]).

After $250 \mathrm{~min}$ of polymerization at 140 and $160{ }^{\circ} \mathrm{C}$, respectively, the conversion is less than $3 \%$ (Figure 1) and less than $8 \%$ (Figure 2). Theses indicate that the $n$-BA self-initiation reaction is slow at $160{ }^{\circ} \mathrm{C}$ or a lower temperature. However, as temperature increases (Figures 3-5), the contribution of self-initiation to the polymerization increases (conversion of more than $25 \%$ at $180^{\circ} \mathrm{C}$, about $40 \%$ at $200{ }^{\circ} \mathrm{C}$, and about $60 \%$ at $220^{\circ} \mathrm{C}$, after $250 \mathrm{~min}$ of reaction). At $160^{\circ} \mathrm{C}$, conversion increases linearly 
from $2.5 \%$ to $6.5 \%$ between 55 and $220 \mathrm{~min}$. At $180{ }^{\circ} \mathrm{C}$, the conversion increases to $25 \%$ after $220 \mathrm{~min}$, and the rate of its increase is slightly higher initially. At $200{ }^{\circ} \mathrm{C}$, a $25 \%$ conversion is achieved after $110 \mathrm{~min}$. Again, the conversion increases faster initially at $200{ }^{\circ} \mathrm{C}$. At $220{ }^{\circ} \mathrm{C}$, less than $55 \mathrm{~min}$ is sufficient to achieve a $30 \%$ conversion. Figures $1-5$ indicate that at $140-220^{\circ} \mathrm{C}$ the conversion does not level off during the $250 \mathrm{~min}$, implying that the polymerization can continue beyond $250 \mathrm{~min}$. Figure 7 shows the high sensitivity of the conversion predictions to the self-initiation rate coefficient, implying the low uncertainty of the estimate of the rate coefficient at each of the temperatures.
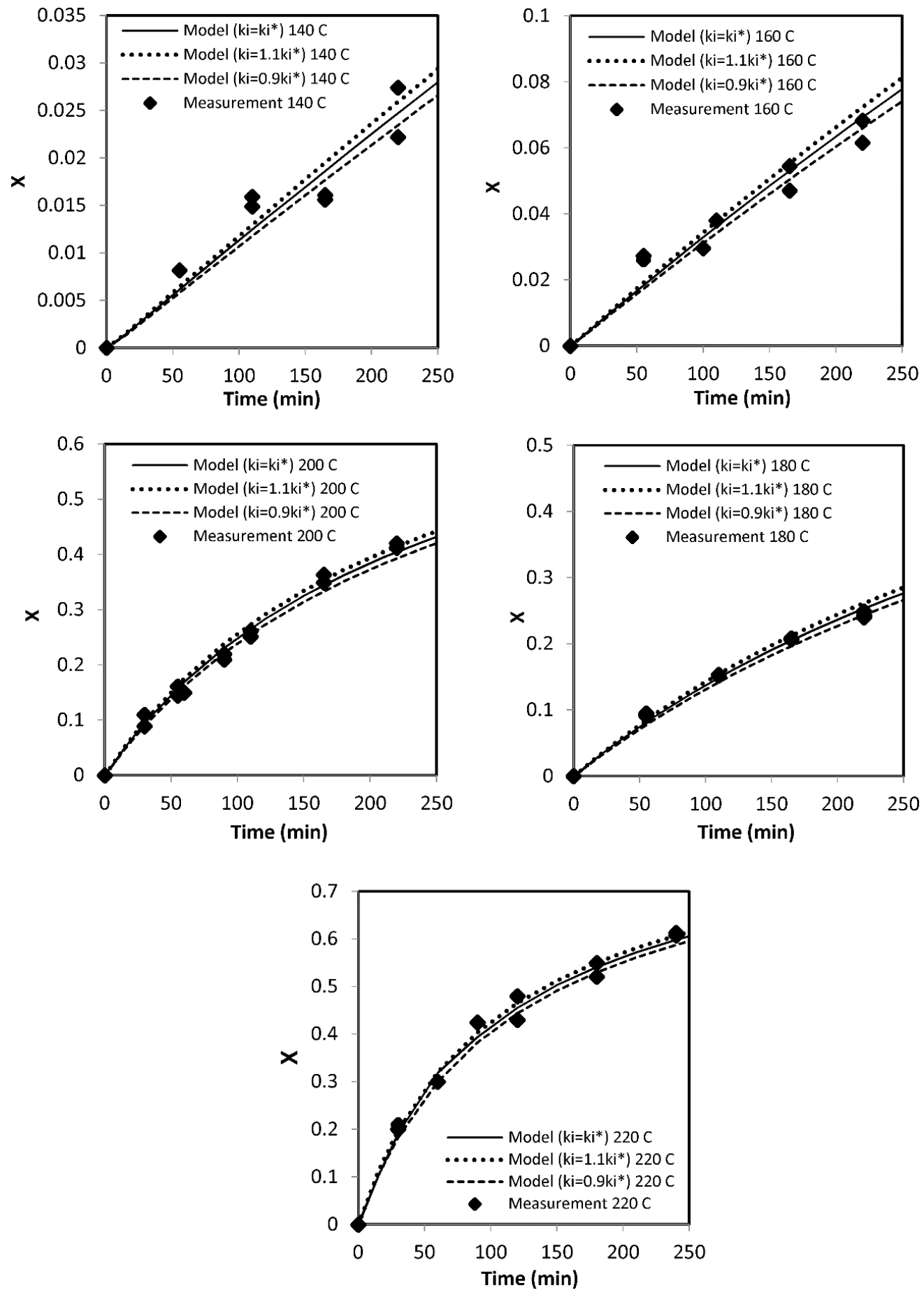

Figure 7. Model prediction and measurements of conversion as well as the sensitivity of predicted conversion to $10 \%$ changes in $k_{i}$ at the five temperatures. 
Table 5. Experimentally-estimated and theoretical values of $k_{i}\left(\mathrm{M}^{-1} \cdot \mathrm{s}^{-1}\right), E_{i}\left(\mathrm{~kJ} \cdot \mathrm{mol}^{-1}\right)$ and $A_{i}\left(\mathrm{M}^{-1} \cdot \mathrm{s}^{-1}\right)$.

\begin{tabular}{cccc}
\hline Temperature & This Work & Theoretical [11] & Theoretical [12] \\
\hline$T$ & $k_{i}$ & $k_{i}$ & $k_{i}$ \\
413 & $3.30 \times 10^{-15}$ & $2.81 \times 10^{-18}$ & $1.04 \times 10^{-14}$ \\
433 & $2.20 \times 10^{-14}$ & $2.86 \times 10^{-17}$ & $4.72 \times 10^{-14}$ \\
453 & $4.00 \times 10^{-13}$ & $2.37 \times 10^{-16}$ & $1.95 \times 10^{-13}$ \\
473 & $1.50 \times 10^{-12}$ & $1.64 \times 10^{-15}$ & $7.11 \times 10^{-13}$ \\
493 & $6.80 \times 10^{-12}$ & $9.74 \times 10^{-15}$ & $2.34 \times 10^{-12}$ \\
\hline Parameter & This Work & Theoretical [11] & Theoretical [12] \\
\hline$E_{i}$ & $165.51 \pm 4.52$ & 172.50 & 115.00 \\
$\ln A_{i}$ & $14.86 \pm 1.20$ & 9.68 & 1.38 \\
\hline
\end{tabular}

\section{Concluding Remarks}

An experimental study of the self-initiation reaction of $n$-BA in free-radical polymerization was presented. The frequency factor and activation energy of the monomer self-initiation reaction were estimated from batch-reactor monomer-conversion measurements from spontaneous polymerization of $n$-BA in the absence of oxygen, using a macroscopic mechanistic mathematical model of the reactor. A comparison of the estimated monomer self-initiation reaction rate constant with estimates obtained via quantum chemical calculations showed satisfactory agreement. These experimental estimates quantify, for the first time, the sole contribution of the monomer self-initiation to the initiation of $n$-BA polymerization.

When two alkyl acrylate monomers react, they form a diradical that undergoes spin transition and subsequently reacts with a third monomer and forms two monoradicals, which initiate polymerization [10-12]. The rate coefficients of alkyl (methyl, ethyl, $n$-butyl) acrylate monomers have similar values [10-12]. However, when two methacylate monomers react, they form a singlet diradical that can undergo three major competing parallel reactions (one generates a dimer and the other two lead to the formation of monoradicals, which initiate polymerization) [13]. Because of the competing parallel reaction that generates a dimer, methacylate monomers have slower monomer-initiated polymerization in comparison with alkyl acrylate monomers.

Acknowledgments: This material is based upon work partially supported by the National Science Foundation under Grant CBET-1160169. A.M.R. acknowledges support from the NSF under grant CBET-1159736. Any opinions, findings, and conclusions or recommendations expressed in this material are those of the authors and do not necessarily reflect the views of the National Science Foundation.

Author Contributions: M.S., A.M.R. and M.C.G. conceived and designed the experiments. A.A.S. and P.C. performed the experiments. N.M. and M.S. derived the reaction rate equations. N.M. and A.A.S. conducted the numerical simulations. S.S., A.A.S., and M.S. analyzed the data. A.A.S., N.M., S.S., A.M.R. and M.S. wrote the paper.

Conflicts of Interest: The authors declare no conflict of interest.

\section{Appendix: Reaction Rate Equations}

$$
\begin{gathered}
r_{M}=-3 k_{i}[M]^{2}-k_{p}[M] \delta_{0}^{*}-k_{p}^{t}[M]\left(\delta_{0}^{* *}+\delta_{0}^{* * *}\right)-k_{t r M}[M] \delta_{0}^{*}-k_{t r M}^{t}[M]\left(\delta_{0}^{* *}+\delta_{0}^{* * *}\right) \\
r_{S}=-k_{t r S}[S] \delta_{0}^{*}-k_{t r S}^{t}[S]\left(\delta_{0}^{* *}+\delta_{0}^{* * *}\right) \\
r_{R_{0}^{*}}=-k_{p}[M]\left[R_{0}^{*}\right]-k_{m a c}\left[R_{0}^{*}\right] \Gamma_{0}-k_{t c}\left[R_{0}^{*}\right] \delta_{0}^{*}-k_{t c}^{t}\left[R_{0}^{*}\right]\left(\delta_{0}^{* *}+\delta_{0}^{* * *}\right)
\end{gathered}
$$




$$
\begin{aligned}
& r_{R_{1}^{*}}=k_{i}[M]^{2}+k_{p}[M]\left(\left[R_{0}^{*}\right]-\left[R_{1}^{*}\right]\right)-k_{m a c}\left[R_{1}^{*}\right] \Gamma_{0}+2 k_{\beta} \delta_{0}^{* *} \\
& +k_{t r m}[M] \delta_{0}^{*}+k_{t r m}^{t}[M]\left(\delta_{0}^{* *}+\delta_{0}^{* * *}\right)-\left(k_{t c}+2 k_{t d}\right)\left[R_{1}^{*}\right] \delta_{0}^{*} \\
& -\left(k_{t c}^{t}+2 k_{t d}^{t}\right)\left[R_{1}^{*}\right]\left(\delta_{0}^{* *}+\delta_{0}^{* * *}\right)-k_{t r p}^{t}\left[R_{1}^{*}\right]\left(\lambda_{1}+\Gamma_{1}\right) \\
& r_{R_{2}^{*}}=k_{i}[M]^{2}+k_{p}[M]\left(\left[R_{1}^{*}\right]-\left[R_{2}^{*}\right]\right)-k_{m a c}\left[R_{2}^{*}\right] \Gamma_{0}+2 k_{\beta}\left(\delta_{0}^{* * *}+2 \delta_{0}^{* *}\right) \\
& -k_{t r P}\left(\lambda_{1}+\Gamma_{1}\right)\left[R_{2}^{*}\right]-\left(k_{t r M}[M]\right)\left[R_{2}^{*}\right]-\left(k_{t c}+2 k_{t d}\right)\left[R_{2}^{*}\right] \delta_{0}^{*} \\
& -\left(k_{t c}^{t}+2 k_{t d}^{t}\right)\left[R_{2}^{*}\right]\left(\delta_{0}^{* *}+\delta_{0}^{* * *}\right) \\
& r_{R_{3}^{*}}=k_{p}[M]\left(\left[R_{2}^{*}\right]-\left[R_{3}^{*}\right]\right)+k_{P}^{t}[M]\left[R_{2}^{* *}\right]-k_{m a c}\left[R_{3}^{*}\right] \Gamma_{0}-k_{b b}\left[R_{3}^{*}\right]+2 k_{\beta} \delta_{0}^{* *} \\
& -k_{t r P}\left(\lambda_{1}+\Gamma_{1}\right)\left[R_{3}^{*}\right]-\left(k_{t r M}[M]\right)\left[R_{3}^{*}\right]-\left(k_{t c}+2 k_{t d}\right)\left[R_{3}^{*}\right] \delta_{0}^{*} \\
& -\left(k_{t c}^{t}+2 k_{t d}^{t}\right)\left[R_{3}^{*}\right]\left(\delta_{0}^{* *}+\delta_{0}^{* * *}\right) \\
& r_{\delta_{0}^{*}}=2 k_{i}[M]^{2}-k_{m a c} \Gamma_{0} \delta_{0}^{*}-k_{b b} \delta_{0}^{*}+2 k_{\beta}\left(\delta_{1}^{* *}-3 \delta_{0}^{* *}+2 \delta_{0}^{* * *}\right)-k_{t r P}\left(\lambda_{1}+\Gamma_{1}\right) \delta_{0}^{*} \\
& +\left(k_{P}^{t}[M]+k_{t r M}^{t}[M]\right)\left(\delta_{0}^{* *}+\delta_{0}^{* * *}\right)-\left(k_{t c}+k_{t d}\right) \delta_{0}^{* 2} \\
& -2\left(k_{t c}^{t}+k_{t d}^{t}\right) \delta_{0}^{*}\left(\delta_{0}^{* *}+\delta_{0}^{* * *}\right) \\
& r_{\delta_{1}^{*}}=3 k_{i}[M]^{2}+k_{p}[M] \delta_{0}^{*}+k_{p}^{t}[M]\left(\delta_{0}^{* *}+\delta_{1}^{* *}+\delta_{0}^{* * *}+\delta_{1}^{* * *}\right)-k_{m a c} \Gamma_{0} \delta_{1}^{*}-k_{b b} \delta_{1}^{*} \\
& +k_{\beta}\left(2 \delta_{1}^{* * *}-2 \delta_{0}^{* * *}+\delta_{2}^{* *}-5 \delta_{1}^{* *}+6 \delta_{0}^{* *}\right)-k_{t r P}\left(\lambda_{1}+\Gamma_{1}\right) \delta_{1}^{*} \\
& +k_{t r M}[M]\left(\delta_{0}^{*}-\delta_{1}^{*}\right)+k_{t r M}^{t}[M]\left(\delta_{0}^{* *}+\delta_{0}^{* * *}\right)-\left(k_{t c}+k_{t d}\right) \delta_{0}^{*} \delta_{1}^{*} \\
& -2\left(k_{t c}^{t}+k_{t d}^{t}\right) \delta_{1}^{*}\left(\delta_{0}^{* *}+\delta_{0}^{* * *}\right) \\
& r_{\delta_{2}^{*}}=5 k_{i}[M]^{2}+k_{p}[M]\left(2 \delta_{1}^{*}+\delta_{0}^{*}\right)+k_{p}^{t}[M]\left(\delta_{2}^{* *}+2 \delta_{1}^{* *}+\delta_{0}^{* *}+\delta_{2}^{* * *}+2 \delta_{1}^{* * *}+\delta_{0}^{* * *}\right) \\
& -k_{m a c} \Gamma_{0} \delta_{2}^{*}-k_{b b} \delta_{2}^{*}-k_{t r P}\left(\lambda_{1}+\Gamma_{1}\right) \delta_{2}^{*}+k_{t r M}[M]\left(\delta_{0}^{*}-\delta_{2}^{*}\right) \\
& +k_{t r M}^{t}[M]\left(\delta_{0}^{* *}+\delta_{0}^{* * *}\right)-\left(k_{t c}+k_{t d}\right) \delta_{0}^{*} \delta_{2}^{*} \\
& -2\left(k_{t c}^{t}+k_{t d}^{t}\right) \delta_{2}^{*}\left(\delta_{0}^{* *}+\delta_{0}^{* * *}\right) \\
& +k_{\beta}\left(2 \delta_{2}^{* * *}-12 \delta_{1}^{* * *}+26 \delta_{0}^{* * *}+\frac{2}{3} \delta_{3}^{* *}-5 \delta_{2}^{* *}+\frac{37}{3} \delta_{1}^{* *}-10 \delta_{0}^{* *}\right) \\
& r_{\delta_{0}^{* *}}^{* *}=-k_{p}^{t}[M] \delta_{0}^{* *}+k_{m a c} \Gamma_{0} \delta_{0}^{*}-2 k_{\beta}\left(\delta_{1}^{* *}-3 \delta_{0}^{* *}\right)+k_{t r P}\left(\lambda_{1}+\Gamma_{1}\right) \delta_{0}^{*}-\left(k_{t r M}^{t}[M]\right) \delta_{0}^{* *} \\
& -2\left(k_{t c}^{t}+k_{t d}^{t}\right) \delta_{0}^{*} \delta_{0}^{* *}-\left(k_{t c}^{t t}+k_{t d}^{t t}\right) \delta_{0}^{* *}\left(\delta_{0}^{* *}+2 \delta_{0}^{* * *}\right) \\
& r_{\delta_{1}^{* *}}^{*}=-k_{p}^{t}[M] \delta_{1}^{* *}+k_{m a c}\left(\delta_{0}^{*} \Gamma_{1}+\delta_{1}^{*} \Gamma_{0}\right)-2 k_{\beta}\left(\delta_{2}^{* *}-3 \delta_{1}^{* *}\right)+k_{t r p} \delta_{0}^{*}\left(\lambda_{2}+\Gamma_{2}\right) \\
& -\left(k_{t r M}^{t}[M]\right) \delta_{1}^{* *}-2\left(k_{t c}^{t}+k_{t d}^{t}\right) \delta_{0}^{*} \delta_{1}^{* *}-\left(k_{t c}^{t t}+k_{t d}^{t t}\right) \delta_{1}^{* *}\left(\delta_{0}^{* *}+2 \delta_{0}^{* * *}\right) \\
& r_{\delta_{2}^{* *}}^{*}=-k_{p}^{t}[M] \delta_{2}^{* *}+k_{m a c}\left(\delta_{0}^{*} \Gamma_{2}+2 \delta_{1}^{*} \Gamma_{1}+\delta_{2}^{*} \Gamma_{0}\right)-2 k_{\beta}\left(\delta_{3}^{* *}-3 \delta_{2}^{* *}\right)+k_{t r P} \delta_{0}^{*} \\
& \left(\Gamma_{3}+\lambda_{3}\right)-\left(k_{t r M}^{t}[M]\right) \delta_{2}^{* *}-2\left(k_{t c}^{t}+k_{t d}^{t}\right) \delta_{0}^{*} \delta_{2}^{* *}-\left(k_{t c}^{t t}+k_{t d}^{t t}\right) \delta_{2}^{* *}\left(\delta_{0}^{* *}+2 \delta_{0}^{* * *}\right) \\
& r_{\delta_{0}^{* * *}}^{* *}=-k_{p}^{t}[M] \delta_{0}^{* * *}+k_{b b} \delta_{0}^{*}-4 k_{\beta} \delta_{0}^{* * *}-\left(k_{t r M}^{t}[M]\right) \delta_{0}^{* * *}-2\left(k_{t c}^{t}+k_{t d}^{t}\right) \delta_{0}^{*} \delta_{0}^{* * *} \\
& -\left(k_{t c}^{t t}+k_{t d}^{t t}\right) \delta_{0}^{* * *}\left(2 \delta_{0}^{* *}+\delta_{0}^{* * *}\right) \\
& r_{\delta_{1}^{* * *}}=-k_{p}^{t}[M] \delta_{1}^{* * *}+k_{b b} \delta_{1}^{*}-4 k_{\beta} \delta_{1}^{* * *}-\left(k_{t r M}^{t}[M]\right) \delta_{1}^{* * *}-2\left(k_{t c}^{t}+k_{t d}^{t}\right) \delta_{0}^{*} \delta_{1}^{* * *} \\
& -\left(k_{t c}^{t t}+k_{t d}^{t t}\right) \delta_{1}^{* * *}\left(2 \delta_{0}^{* *}+\delta_{0}^{* * *}\right) \\
& r_{\delta_{2}^{* * *}}=-k_{p}^{t}[M]\left[\delta_{2}^{* * *}\right]+k_{b b} \delta_{2}^{*}-4 k_{\beta} \delta_{2}^{* * *}-\left(k_{t r M}^{t}[M]\right) \delta_{2}^{* * *}-2\left(k_{t c}^{t}+k_{t d}^{t}\right) \delta_{0}^{*} \delta_{2}^{* * *} \\
& -\left(k_{t c}^{t t}+k_{t d}^{t t}\right) \delta_{2}^{* * *}\left(2 \delta_{0}^{* *}+\delta_{0}^{* * *}\right)
\end{aligned}
$$




$$
\begin{aligned}
& r_{\lambda_{0}}=k_{t r P} \delta_{0}^{*} \Gamma_{1}+\left(k_{t r M}[M]\right) \delta_{0}^{*}+\left(k_{t r M}^{t}[M]\right)\left(\delta_{0}^{* *}+\delta_{0}^{* * *}\right)+0.5\left(k_{t c}+k_{t d}\right) \delta_{0}^{*} \delta_{0}^{*} \\
& +2\left(k_{t c}^{t}+k_{t d}^{t}\right) \delta_{0}^{*}\left(\delta_{0}^{* *}+\delta_{0}^{* * *}\right) \\
& +0.5\left(k_{t c}^{t t}+k_{t d}^{t t}\right)\left(\delta_{0}^{* *} \delta_{0}^{* *}+\delta_{0}^{* * *} \delta_{0}^{* * *}+4 \delta_{0}^{* *} \delta_{0}^{* * *}\right) \\
& r_{\lambda_{1}}=k_{t r P}\left(\delta_{1}^{*}\left(\Gamma_{1}+\lambda_{1}\right)-\delta_{0}^{*} \lambda_{2}\right)+\left(k_{t r M}[M]\right) \delta_{1}^{*}+\left(k_{t r M}^{t}[M]\right)\left(\delta_{1}^{* *}+\delta_{1}^{* * *}\right) \\
& +0.5\left(2 k_{t c}+k_{t d}\right) \delta_{0}^{*} \delta_{1}^{*} \\
& +\left(2 k_{t c}^{t}+k_{t d}^{t}\right)\left(\delta_{1}^{*} \delta_{0}^{* *}+\delta_{1}^{* *} \delta_{0}^{*}+\delta_{1}^{*} \delta_{0}^{* * *}+\delta_{1}^{* * *} \delta_{0}^{*}\right) \\
& +\left(2 k_{t c}^{t t}+k_{t d}^{t t}\right)\left(0.5 \delta_{0}^{* *} \delta_{1}^{* *}+0.5 \delta_{0}^{* * *} \delta_{1}^{* * *}+\delta_{1}^{* *} \delta_{0}^{* * *}+\delta_{0}^{* *} \delta_{1}^{* * *}\right) \\
& r_{\lambda_{2}}=k_{t r P}\left(\delta_{2}^{*}\left(\Gamma_{1}+\lambda_{1}\right)-\delta_{0}^{*} \lambda_{3}\right)+\left(k_{t r M}[M]\right) \delta_{2}^{*}+\left(k_{t r M}^{t}[M]\right)\left(\delta_{2}^{* *}+\delta_{2}^{* * *}\right)+k_{t c}\left(\delta_{0}^{*} \delta_{2}^{*}+\delta_{1}^{*} \delta_{1}^{*}\right) \\
& +2 k_{t c}^{t}\left(\delta_{2}^{*}\left(\delta_{0}^{* *}+\delta_{0}^{* * *}\right)+2 \delta_{1}^{*}\left(\delta_{1}^{* *}+\delta_{1}^{* * *}\right)+\delta_{0}^{*}\left(\delta_{2}^{* *}+\delta_{2}^{* * *}\right)\right) \\
& +k_{t c}^{t t}\left(\delta_{2}^{* *} \delta_{0}^{* *}+\delta_{1}^{* *} \delta_{1}^{* *}+\delta_{2}^{* * *} \delta_{0}^{* * *}+\delta_{1}^{* * *} \delta_{1}^{* * *}+2 \delta_{0}^{* * *} \delta_{2}^{* *}+2 \delta_{2}^{* * *} \delta_{0}^{* *}\right. \\
& \left.+4 \delta_{1}^{* * *} \delta_{1}^{* *}\right)+0.5 k_{t d} \delta_{0}^{*} \delta_{2}^{*}+k_{t d}^{t}\left(\delta_{0}^{* *} \delta_{2}^{*}+\delta_{0}^{*} \delta_{2}^{* *}+\delta_{0}^{* * *} \delta_{2}^{*}+\delta_{2}^{* * *} \delta_{0}^{*}\right) \\
& +k_{t d}^{t t}\left(0.5 \delta_{0}^{* *} \delta_{2}^{* *}+0.5 \delta_{0}^{* * *} \delta_{2}^{* * *}+\delta_{2}^{* *} \delta_{0}^{* * *}+\delta_{2}^{* * *} \delta_{0}^{* *}\right) \\
& r_{\Gamma_{0}}=-k_{\operatorname{mac}} \delta_{0}^{*} \Gamma_{0}+2 k_{\beta}\left(2 \delta_{0}^{* * *}+\delta_{1}^{* *}-3 \delta_{0}^{* *}\right)-k_{t r P} \delta_{0}^{*} \Gamma_{1}+0.5 k_{t d} \delta_{0}^{* 2} \\
& +2 k_{t d}^{t} \delta_{0}^{*}\left(\delta_{0}^{* *}+\delta_{0}^{* * *}\right)+0.5 k_{t d}^{t t}\left(\delta_{0}^{* *} \delta_{0}^{* *}+4 \delta_{0}^{* *} \delta_{0}^{* * *}+\delta_{0}^{* * *} \delta_{0}^{* * *}\right) \\
& r_{\Gamma_{1}}=-k_{\text {mac }} \delta_{0}^{*} \Gamma_{1}+k_{\beta}\left(2 \delta_{1}^{* * *}+2 \delta_{0}^{* * *}+\delta_{2}^{* *}-\delta_{1}^{* *}-6 \delta_{0}^{* *}\right)-k_{t r P} \delta_{0}^{*} \Gamma_{2}+0.5 k_{t d} \delta_{0}^{*} \delta_{1}^{*} \\
& +k_{t d}^{t}\left(\delta_{1}^{*} \delta_{0}^{* *}+\delta_{1}^{* *} \delta_{0}^{*}+\delta_{0}^{* * *} \delta_{1}^{*}+\delta_{0}^{*} \delta_{1}^{* * *}\right) \\
& +0.5 k_{t d}^{t t}\left(\delta_{0}^{* *} \delta_{1}^{* *}+\delta_{0}^{* * *} \delta_{1}^{* * *}+2 \delta_{1}^{* *} \delta_{0}^{* * *}+2 \delta_{0}^{* *} \delta_{1}^{* * *}\right) \\
& r_{\Gamma_{2}}=-k_{\operatorname{mac}} \delta_{0}^{*} \Gamma_{2} \\
& +k_{\beta}\left(2 \delta_{2}^{* * *}-8 \delta_{1}^{* * *}+26 \delta_{0}^{* * *}+\frac{2}{3} \delta_{3}^{* *}-\delta_{2}^{* *}+\frac{1}{3} \delta_{1}^{* *}\right. \\
& \left.-10 \delta_{0}^{* *}\right)-k_{t r P} \delta_{0}^{*} \Gamma_{3}+0.5 k_{t d} \delta_{0}^{*} \delta_{2}^{*} \\
& +k_{t d}^{t}\left(\delta_{0}^{*}\left(\delta_{2}^{* *}+\delta_{2}^{* * *}\right)+\delta_{2}^{*}\left(\delta_{0}^{* *}+\delta_{0}^{* * *}\right)\right) \\
& +k_{t d}^{t t}\left(0.5 \delta_{0}^{* * *} \delta_{2}^{* * *}+0.5 \delta_{0}^{* *} \delta_{2}^{* *}+\delta_{0}^{* * *} \delta_{2}^{* *}+\delta_{0}^{* *} \delta_{2}^{* * *}\right)
\end{aligned}
$$

where (assuming re-scaled Gamma distributions for the dead polymer chains and a normal distribution for the tertiary radicals $R_{n}^{* *}$ )

$$
\begin{gathered}
\lambda_{3} \approx\left(\frac{\lambda_{2}}{\lambda_{0} \lambda_{1}}\right)\left(2 \lambda_{0} \lambda_{2}-\lambda_{1}^{2}\right) \\
\Gamma_{3} \approx\left(\frac{\Gamma_{2}}{\Gamma_{0} \Gamma_{1}}\right)\left(2 \Gamma_{0} \Gamma_{2}-\Gamma_{1}^{2}\right) \\
\delta_{3}^{* *} \approx 3 \delta_{2}^{* *} \delta_{1}^{* *}-2 \delta_{1}^{* * 3}
\end{gathered}
$$

\section{References}

1. Consumer and Commercial Products, Group IV: Control Techniques Guidelines in Lieu of Regulations for Miscellaneous Metal Products Coatings, Plastic Parts Coatings, Auto and Light-Duty Truck Assembly Coatings, Fiberglass Boat Manufacturing Materials, and Miscellaneous Industrial Adhesives; EPA-HQ-OAR-2008-0411; FRL-8725-9; Environmental Protection Agency: Washington, DC, USA, 2008; Volume 73, No. 195; pp. 58481-58490.

2. Economic Impact and Regulatory Flexibility Analyses of the Final Architectural Coatings VOC Rule; EPA-452/R-98-002; United States Environmental Protection Agency, Office of Air Quality Planning and Standards: Washington, DC, USA, 1998. 
3. Campbell, J.D.; Teymour, F.; Morbidelli, M. High temperature free radical polymerization. 1. Investigation of continuous styrene polymerization. Macromolecules 2003, 36, 5491-5501. [CrossRef]

4. Wang, W.; Hutchinson, R.A. Recent advances in the study of high-temperature free radical acrylic solution copolymerization. Macromol. React. Eng. 2008, 2, 199-214. [CrossRef]

5. Grady, M.C.; Simonsick, W.J.; Hutchinson, R.A. Studies of higher temperature polymerization of n-butyl methacrylate and n-butyl acrylate. Macromol. Symp. 2002, 182, 149-168. [CrossRef]

6. Soroush, M.; Grady, M.C.; Kalfas, G.A. Free-radical polymerization at higher temperatures: Systems impacts of secondary reactions. Comput. Chem. Eng. 2008, 32, 2155-2167. [CrossRef]

7. Quan, C.L.; Soroush, M.; Grady, M.C.; Hansen, J.E.; Simonsick, W.J. High-temperature homopolymerization of ethyl acrylate and n-butyl acrylate: Polymer characterization. Macromolecules 2005, 38, 7619-7628. [CrossRef]

8. Chiefari, J.; Jeffery, J.; Mayadunne, R.T.A.; Moad, G.; Rizzardo, E.; Thang, S.H. Chain transfer to polymer: A convenient route to macromonomers. Macromolecules 1999, 32, 7700-7702. [CrossRef]

9. Rantow, F.S.; Soroush, M.; Grady, M.C.; Kalfas, G.A. Spontaneous polymerization and chain microstructure evolution in high-temperature solution polymerization of n-butyl acrylate. Polymer 2006, 47, 1423-1435. [CrossRef]

10. Srinivasan, S.; Lee, M.W.; Grady, M.C.; Soroush, M.; Rappe, A.M. Computational study of the self-initiation mechanism in thermal polymerization of methyl acrylate. J. Phys. Chem. A 2009, 113, 10787-10794. [CrossRef] [PubMed]

11. Srinivasan, S.; Lee, M.W.; Grady, M.C.; Soroush, M.; Rappe, A.M. Self-initiation mechanism in spontaneous thermal polymerization of ethyl and n-butyl acrylate: A theoretical study. J. Phys. Chem. A 2010, 114, 7975-7983. [CrossRef] [PubMed]

12. Liu, S.; Srinivasan, S.; Tao, J.; Grady, M.C.; Soroush, M.; Rappe, A.M. Modeling Spin-Forbidden Monomer Self-initiation Reactions in Free-Radical Polymerization of Acrylates and Methacrylates. J. Phys. Chem. A 2014, 118, 9310-9318. [CrossRef] [PubMed]

13. Srinivasan, S.; Lee, M.W.; Grady, M.C.; Soroush, M.; Rappe, A.M. Computational Evidence for Self-Initiation in Spontaneous High-Temperature Polymerization of Methyl Methacrylate. J. Phys. Chem. A 2011, 115, 1125-1132. [CrossRef] [PubMed]

14. Srinivasan, S.; Kalfas, G.; Petkovska, V.I.; Bruni, C.; Grady, M.C.; Soroush, M. Experimental study of the spontaneous thermal homopolymerization of methyl and n-butyl acrylate. J. Appl. Polym. Sci. 2010, 118, 1898-1909. [CrossRef]

15. Arzamendi, G.; Plessis, C.; Leiza, J.R.; Asua, J.M. Effect of the intramolecular chain transfer to polymer on PLP/SEC experiments of alkyl acrylates. Macromol. Theory Simul. 2003, 12, 315-324. [CrossRef]

16. Nikitin, A.N.; Hutchinson, R.A.; Buback, M.; Hesse, P. Determination of intramolecular chain transfer and midchain radical propagation rate coefficients for butyl acrylate by pulsed laser polymerization. Macromolecules 2007, 40, 8631-8641. [CrossRef]

17. Buback, M.; Gilbert, R.G.; Hutchinson, R.A.; Klumperman, B.; Kuchta, F.D.; Manders, B.G.; Odriscoll, K.F.; Russell, G.T.; Schweer, J. Critically evaluated rate coefficients for free-radical polymerization. 1. Propagation rate coefficient for styrene. Macromol. Chem. Phys. 1995, 196, 3267-3280.

18. Beuermann, S.; Buback, M.; Davis, T.P.; Gilbert, R.G.; Hutchinson, R.A.; Olaj, O.F.; Russell, G.T.; Schweer, J.; vanHerk, A.M. Critically evaluated rate coefficients for free-radical polymerization. 2. Propagation rate coefficients for methyl methacrylate. Macromol. Chem. Phys. 1997, 198, 1545-1560. [CrossRef]

19. Nikitin, A.N.; Hutchinson, R.A.; Buback, M.; Hesse, P. A novel approach for investigation of chain transfer events by pulsed laser polymerization. Macromol. Chem. Phys. 2011, 212, 699-707. [CrossRef]

20. Barner-Kowollik, C.; Gunzler, F.; Junkers, T. Pushing the Limit: Pulsed Laser Polymerization of n-Butyl Acrylate at $500 \mathrm{~Hz}$. Macromolecules 2008, 41, 8971-8973. [CrossRef]

21. Lyons, R.A.; Hutovic, J.; Piton, M.C.; Christie, D.I.; Clay, P.A.; Manders, B.G.; Kable, S.H.; Gilbert, R.G. Pulsed-laser polymerization measurements of the propagation rate coefficient for butyl acrylate. Macromolecules 1996, 29, 1918-1927. [CrossRef]

22. Beuermann, S.; Paquet, D.A.; McMinn, J.H.; Hutchinson, R.A. Determination of free-radical propagation rate coefficients of butyl, 2-ethylhexyl, and dodecyl acrylates by pulsed-laser polymerization. Macromolecules 1996, 29, 4206-4215. [CrossRef] 
23. Busch, M.; Wahl, A. The significance of transfer reactions in pulsed laser polymerization experiments. Macromol. Theory Simul. 1998, 7, 217-224. [CrossRef]

24. Ahmad, N.M.; Heatley, F.; Lovell, P.A. Chain transfer to polymer in free-radical solution polymerization of n-butyl acrylate studied by NMR spectroscopy. Macromolecules 1998, 31, 2822-2827. [CrossRef]

25. Peck, A.N.F.; Hutchinson, R.A. Secondary reactions in the high-temperature free radical polymerization of butyl acrylate. Macromolecules 2004, 37, 5944-5951. [CrossRef]

26. Heatley, F.; Lovell, P.A.; Yamashita, T. Chain transfer to polymer in free-radical solution polymerization of 2-ethylhexyl acrylate studied by NMR spectroscopy. Macromolecules 2001, 34, 7636-7641. [CrossRef]

27. Stickler, M.; Meyerhoff, G. The spontaneous thermal polymerization of mthyl-methacrylate: 5. Experimental-study and computer-simulation of the high conversion reaction at $130^{\circ} \mathrm{C}$. Polymer 1981, 22, 928-933. [CrossRef]

28. Blavier, L.; Villermaux, J. Free-radical polymerization engineering: 2. Modeling of homogeneous polymerization of styrene in a batch reactor, influence of initiator. Chem. Eng. Sci. 1984, 39, 101-110. [CrossRef]

29. Rier, T.; Srinivasan, S.; Soroush, M.; Kalfas, G.A.; Grady, M.C.; Rappe, A.M. Macroscopic mechanistic modeling and optimization of a self-initiated high-temperature polymerization reactor. In Proceedings of the 2011 American Control Conference, San Francisco, CA, USA, 29 June 2011-1 July 2011; pp. 3071-3076.

30. Asua, J.M.; Beuermann, S.; Buback, M.; Castignolles, P.; Charleux, B.; Gilbert, R.G.; Hutchinson, R.A.; Leiza, J.R.; Nikitin, A.N. Critically evaluated rate coefficients for free-radical polymerization, 5-Propagation rate coefficient for butyl acrylate. Macromol. Chem. Phys. 2004, 205, 2151-2160. [CrossRef]

31. Nikitin, A.N.; Hutchinson, R.A. Effect of intramolecular transfer to polymer on stationary free radical polymerization of alkyl acrylates, 2-Improved consideration of termination. Macromol. Theory Simul. 2006, 15, 128-136. [CrossRef]

32. Wang, W.; Nikitin, A.N.; Hutchinson, R.A. Consideration of macromonomer reactions in n-butyl acrylate free radical polymerization. Macromol. Rapid Commun. 2009, 30, 2022-2027. [CrossRef] [PubMed]

33. Nikitin, A.N.; Hutchinson, R.A.; Kalfas, G.A.; Richards, J.R.; Bruni, C. The effect of intramolecular transfer to polymer on stationary free-radical polymerization of alkyl acrylates, 3-Consideration of solution polymerization up to high conversions. Macromol. Theory Simul. 2009, 18, 247-258. [CrossRef]

34. Nikitin, A.N.; Hutchinson, R.A.; Wang, W.; Kalfas, G.A.; Richards, J.R.; Bruni, C. Effect of intramolecular transfer to polymer on stationary free-radical polymerization of alkyl acrylates, 5-Consideration of solution polymerization up to high temperatures. Macromol. React. Eng. 2010, 4, 691-706. [CrossRef]

35. Yu, X. Kinetic Modeling of Acrylate Polymerization at High Temperature. Ph.D. Thesis, Northwestern University, Evanston, IL, USA, 2008.

36. Kruse, T.M.; Woo, O.S.; Broadbelt, L.J. Detailed mechanistic modeling of polymer degradation: Application to polystyrene. Chem. Eng. Sci. 2001, 56, 971-979. [CrossRef]

37. Zhu, S.P. Modeling of molecular weight development in atom transfer radical polymerization. Macromol. Theory Simul. 1999, 8, 29-37. [CrossRef]

38. Villermaux, J.; Blavier, L. Free-radical polymerization engineering. 1. A new method for modeling free-radical homogeneous polymerization reactions. Chem. Eng. Sci. 1984, 39, 87-99. [CrossRef]

39. Kim, D.M.; Iedema, P.D. Modeling of branching density and branching distribution in low-density polyethylene polymerization. Chem. Eng. Sci. 2008, 63, 2035-2046. [CrossRef]

40. Benyahia, B.; Latifi, M.A.; Fonteix, C.; Pla, F.; Nacef, S. Emulsion copolymerization of styrene and butyl acrylate in the presence of a chain transfer agent. Part 1: Modelling and experimentation of batch and fedbatch processes. Chem. Eng. Sci. 2010, 65, 850-869. [CrossRef]

41. Martinez, E.C. Model discrimination and selection in evolutionary optimization of batch processes with tendency models. Comput. Aided Chem. Eng. 2005, 20, 463-468.

42. Fotopoulos, J.; Georgakis, C.; Stenger, H.G. Use of tendency models and their uncertainty in the design of state estimators for batch reactors. Chem. Eng. Process. 1998, 37, 545-558. [CrossRef]

43. Fotopoulos, J.; Georgakis, C.; Stenger, H.G. Effect of process-model mismatch on the optimization of the catalytic epoxidation of oleic acid using tendency models. Chem. Eng. Sci. 1996, 51, 1899-1908. [CrossRef]

44. Filippi, C.; Greffe, J.L.; Bordet, J.; Villermaux, J.; Barnay, J.L.; Bonte, P.; Georgakis, C. Tendency modeling of semibatch reactors for optimization and control. Chem. Eng. Sci. 1986, 41, 913-920. [CrossRef] 
45. Martinez, E.C.; Cristaldi, M.D.; Grau, R.J. Design of dynamic experiments in modeling for optimization of batch processes. Ind. Eng. Chem. Res. 2009, 48, 3453-3465. [CrossRef]

46. Mueller, P.A.; Richards, J.R.; Congalidis, J.P. Polymerization reactor modeling in industry. Macromol. React. Eng. 2011, 5, 261-277. [CrossRef]

47. Maeder, S.; Gilbert, R.G. Measurement of transfer constant for butyl acrylate free-radical polymerization. Macromolecules 1998, 31, 4410-4418. [CrossRef]

48. Moad, G.; Solomon, D.H. The Chemistry of Free Radical Polymerization; Elsevier: Oxford, UK, 1995.

49. Derboven, P.; D’hooge, D.R.; Reyniers, M.-F.; Marin, G.B.; Barner-Kowollik, C. The long and the short of radical polymerization. Macromolecules 2015, 48, 492-501. [CrossRef]

50. Barth, J.; Buback, M.; Hesse, P.; Sergeeva, T. Termination and transfer kinetics of butyl acrylate radical polymerization studies via SP-PLP-EPR. Macromolecules 2010, 43, 4023-4031. [CrossRef]

51. Hulburt, H.M.; Katz, S. Some problems in particle technology. Chem. Eng. Sci. 1964, 19, 555-574. [CrossRef]

(C) 2016 by the authors; licensee MDPI, Basel, Switzerland. This article is an open access article distributed under the terms and conditions of the Creative Commons Attribution (CC-BY) license (http:/ / creativecommons.org/licenses/by/4.0/). 